\title{
Single Nucleotide Polymorphisms in Bmy1 Intron III Alleles Conferring the Genotypic Variation in $\beta$ - amylase Activity under Drought Stress Between Tibetan Wild and Cultivated Barley
}

\section{Xiaojian Wu}

Zhejiang Academy of Agricultural Sciences

\section{Huan Wang}

Zhejiang University - Zijingang Campus: Zhejiang University

\section{Fanrong Zeng}

Zhejiang University - Zijingang Campus: Zhejiang University

Junmei Wang ( $D$ 21wangjm@sina.com )

Zhejiang Academy of Agricultural Sciences https://orcid.org/0000-0003-1008-460X

\section{Research Article}

Keywords: Drought, Bmy1 intron III, Allele, $\beta$-amylase activity, Cultivated barley (Hordeum vulgare L.), Wild barley (Hoedeum spontaneum)

Posted Date: August 12th, 2021

DOI: https://doi.org/10.21203/rs.3.rs-790936/v1

License: (c) (i) This work is licensed under a Creative Commons Attribution 4.0 International License.

Read Full License 


\section{Abstract}

$\beta$-amylase activity is related to the polymorphism of Bmy1 intron IIl; however, no attention has been given to such relationship under environmental stresses like drought. In this study, 73 cultivated barley genotypes and 52 Tibetan wild barley accessions were used to test the association between Bmy1 gene intron III polymorphisms and $\beta$-amylase activity under drought stress. Our results showed that three alleles, Bmy1.a, Bmy1.b and Bmy1.c, existed in the examined barley genotypes. Tibetan wild barley had higher proportion of Bmy1.b, whereas cultivated barley showed higher proportion of Bmy1.a. Impressively, barley genotypes with Bmy1.b showed significant increase in $\beta$-amylase activity under drought stress, compared with those with Bmy1.a or Bmy1.c, indicating that Bmy1.b allele might provide more chances for developing barley cultivars with higher $\beta$-amylase activity under water stress than both Bmy1.a and Bmy1.c alleles. Furthermore, the Tibetan wild barley XZ147, belonging to Bmy 1.b allele type, showed significant higher $\beta$-amylase activity than the cultivar Triumph under drought stress. This might result from the unique amino acid substitution M527 or the amino acid composition of R115, D165, A233, S347 and M527 of XZ147.

\section{Introduction}

Barley (Hordeum vulgare L.) is widely used for malting to produce beer and whisky. In brewing industry, one of the most important malt quality parameters is diastatic power (DP), which refers to starchdegrading ability of barley. DP represents a general ability of four major enzymes, i.e. a-amylase, $\beta$ amylase, limit dextrinase and a-glucosidase, $\beta$-amylase (EC 3.2.1.2; 1, 4- $\beta$-glucan maltohydrolase), which catalyzes $\beta$-maltose released from none-reducing end of poly-glucan chain, is the predominant enzyme affecting DP (Arends et al. 1995; Delcour and Verschaeve 1987; Gibson et al. 1995).

Genes controlling $\beta$-amylase synthesis may differ among plant tissues; however, their functional domain should be similar because all of them belong to the same gene family. In malting barley, $\beta$-amylase activity is an important quality trait, being closely associated with malt quality (Arends et al. 1995). There are two forms of $\beta$-amylase expressed in barley. The endosperm specific form is a dominant one, which encoded by Bmy 1 gene, about $5 \mathrm{kbp}$, located on the long arm telomere of $4 \mathrm{H}$ chromosome (Nielsen et al. 1983; Powling et al. 1981). It consists of 7 extrons and 6 introns, and encodes a polypeptide chain of 535 amino acids (Kreis et al. 1988; Yoshigi et al. 1994). The Bmy 1 gene was closely correlated with DP (Hayes et al. 1993). The polymorphisms in the intron III of Bmy 1 are extremely abundant. There are four different allele types according to the presence and absence of 4 insertion/deletions (INDELs) (126-, 38-, 11- and 21-bp), namely Bmy1.a, Bmy1.b, Bmy1.c and Bmy1.d (Vinje et al., 2010). Erkkilä et al. (1998) identified two different indels (126-bp and 38-bp) through southern blot analysis using the first 320bp located at the 5 ' region of Bmy 1 intron III. Currently, all these four types of alleles derived from Bmy 1 intron III INDELs have been identified, including the insertion of 126-bp and 38-bp in the cultivated barley Adorra, and the deletion of 126-bp and 38-bp INDELs in the wild barley PI 296897 (Erkkilä et al. 1998). Sjakste and Zhuk (2006) also observed abundant polymorphisms of Bmy1 intron III, and found a potential binding site for a transcript factor. Numerous studies have confirmed that the polymorphism of Bmy 1 
intron III is correlated with enzyme activity, thermal stability and enzymatic kinetics of $\beta$-amylase (Erkkilä et al. 1998; Erkkilä and Ahokas 2001; Kaneko et al. 2000; Ma et al. 2001; Paris et al. 2002). Erkkilä and Ahokas (2001) and Gunkel et al. (2002) reported that the presence or deletion of a 126-bp INDEL in the 5' end of Bmy 1 intron III was associated with low activity and high thermal stability of $\beta$-amylase, respectively. Coventry et al. (2003) determined the activity and thermal stability of $\beta$-amylase, and DP value and identified a primer pair which could discriminate the presence or absence of the 126-bp INDEL. Meanwhile, the Single Nucleotide Polymorphisms (SNPs) in the coding region of Bmy 1 also affected $\beta$ amylase morphology, activity and thermal stability of the enzyme (Li et al. 2001). All these studies indicate that it is practicable to identify enzyme activity and thermal stability of $\beta$-amylase by only detecting the polymorphisms of either coding or noncoding regions of Bmy1 under normal environmental condition. However, little attention has been given to this issue under the environmental stresses like drought.

Tibetan wild barley is considered as one of ancestors of modern cultivated barley, rich in genetic diversity (Dai et al. 2012). Till the present, however, most studies about the wild barley are mainly concentrated on salinity tolerance (Qiu et al. 2011), aluminum tolerance (Dai et al. 2011) and grain protein content (Wei et al. 2009), and no research has been done to investigate the genetic variation of malt quality under drought stress. In this study, we used 73 cultivated and 52 Tibetan wild barley genotypes to investigate the correlation between Bmy 1 intron III polymorphism and grain $\beta$-amylase activity under drought stress, and to compare the difference between wild and cultivated barley.

\section{Materials And Methods}

\section{Plant cultivation and drought treatment}

In the present study, 73 cultivated barley genotypes and 52 Tibetan wild barley accessions were used (Supplemental Table S1). All genotypes or accessions were sown in mid-November 2018, and grew in two rain shelters $(60 \mathrm{~m} \times 20 \mathrm{~m})$ in Changxing experimental station of Zhejiang University (Huzhou, Zhejiang province, China) for control and drought stress respectively. The experiment was arranged in random block design, with three replicates for each treatment. In each replicate, every barley genotype was sown in three rows, and only the grains from the middle line were harvested for the following investigations.

After germination, all barley plants in two rain shelters were well-irrigated with a sprinkling irrigation system, to keep the soil water content around $35 \%$ (equaling to water potential of $-0.15 \mathrm{MPa}$, monitored by $\mathrm{HH} 2$ Moisture Meter, Delta-T Devices, Cambridge, UK). When approximately $85 \%$ of barley genotypes reached the heading stage, drought stress was started when approximately $85 \%$ of barley genotypes were at heading stage, by stopping water supply until the soil water content dropped to $14 \%$ (equaling to water potential of $-0.75 \mathrm{MPa}$ ). The drought stressed barley plants were thereafter kept this water level to the maturity stage, whereas the control plants were maintained normal water supply to keep soil water content around $35 \%$. During drought treatment, soil water contents in the two rain shelters were 
monitored every three days by randomly measuring soil water content at 30 positions over the whole shelter.

To analyze the polymorphism of Bmy 1 gene, seeds of each barley genotype were surface sterilized with $12.5 \% \mathrm{NaClO}$ solution, thoroughly rinsed with tap water (for at least $30 \mathrm{~min}$ ) and then grown using paper roll with $1 / 5$ strength of Hoagland solution in the well-controlled growth chamber, with a day-length of 14 h; light/dark temperatures, $23 / 16^{\circ} \mathrm{C}$; and relative humidity, $65 \%$ at Zhejiang University, China. The first fully expanded leaf was collected to extract DNA for further investigations.

\section{Measurement of $\beta$-amylase activity}

Grains of each barley genotype were harvested at its respective maturity, dried at $40^{\circ} \mathrm{C}$, milled to pass through $0.5 \mathrm{~mm}$ sieve, and then store at $-20^{\circ} \mathrm{C}$ for further use.

$\beta$-amylase activity was measured using a Betamyl assay kit (Megazyme International, Ireland Ltd.) according to McCleary and Codd (1989).

\section{DNA extraction}

DNA extraction was conducted according to the CTAB (hexadecyltrimethyl ammonium bromide) protocol with the following procedures: approximately $0.5 \mathrm{~g}$ leaf tissues were fine-grounded in liquid nitrogen and transferred to a $2 \mathrm{~mL}$ centrifuge tube containing $1 \mathrm{~mL}$ CTAB buffer ( $2 \% \mathrm{w} / \mathrm{v}$ CTAB, $1.42 \mathrm{M} \mathrm{NaCl}, 20 \mathrm{mM}$ EDTA, $100 \mathrm{mM}$ Tris- $\mathrm{HCl}$, and $0.2 \% \beta$-mercaptoethanol, preheated to $60^{\circ} \mathrm{C}$ ). After incubated in the water bath $\left(65^{\circ} \mathrm{C}\right)$ for $30 \mathrm{~min}$, the leaf extract was thoroughly mixed with $750 \mu \mathrm{L}$ chloroform: isoamylol $(24: 1)$ solution by vortex shaking and then centrifuged at $12000 \mathrm{rpm}$ for $10 \mathrm{~min}$ at $4^{\circ} \mathrm{C}$. The supernatant was transferred to a new tube and treated with chloroform: isoamylol solution to make the DNA extraction purer. Thereafter, the supernatant was then well mixed with $0.7 \mathrm{v} / \mathrm{v}$ isopropanol, placed at room temperature for $10 \mathrm{~min}$ and centrifuged again at $12000 \mathrm{rpm} 10 \mathrm{~min}$ at $4^{\circ} \mathrm{C}$. The supernatant was discarded and the pellet was washed with $1000 \mu \mathrm{l}$ of $70 \%$ ethanol and then centrifuged at $12000 \mathrm{rpm}$ for $15 \mathrm{~min}$ at room temperature. The cleaned pellet was later dried in air, suspended with $15-20 \mu \mathrm{l}$ of $0.1 \mathrm{M}$ $\mathrm{TE}$, and then stored at $-20^{\circ} \mathrm{C}$ for the following detection.

\section{Polymorphism analysis of Bmy1 gene, cloning and sequencing of Bmy1 intron III}

According to Hayden et al. (2008), 12 Simple Sequence Repeat (SSR) marker primers (Table 1) were used to screen Bmy1 diversity. PCR products were analyzed by scoring the presence of a band as 1 and the absence as 0 . All the data was imported into SPSS using Hierarchical Cluster Analysis with default settings to conduct cluster analysis (Fig. 1). 
Table 1

Primer sequences of SSR assays.

\begin{tabular}{|c|c|c|c|}
\hline \multirow[t]{2}{*}{ hvSSR } & Primer $\left(5^{\prime} \rightarrow 3^{\prime}\right)$ & \multirow[t]{2}{*}{ PCR size } & \multirow[t]{2}{*}{ Allele size } \\
\hline & Primer $\left(5^{\prime} \rightarrow 3^{\prime}\right)$ & & \\
\hline \multirow[t]{2}{*}{ hv1006 } & Cagacafttcacccataagct & 458 & $437-458$ \\
\hline & $\operatorname{tgctgctgctttgaagtctgc}$ & & \\
\hline \multirow[t]{2}{*}{ hv1010 } & Cctcaaaatttgcaggtagcat & 304 & $209-304$ \\
\hline & tggtgtgtaaaccattgccttc & & \\
\hline \multirow[t]{2}{*}{ hv1013 } & Gatgagcgcaccagaagaact & 266 & $222-266$ \\
\hline & Ccctctctccatccagcactc & & \\
\hline \multirow[t]{2}{*}{ hv1014 } & Ttgttgatttgcaggtgccta & 147 & $144-147$ \\
\hline & Tcgatatttctggccctgatc & & \\
\hline \multirow[t]{2}{*}{ hv1015 } & Caattgctgaaaggcatgaaa & 369 & $352-369$ \\
\hline & gccacccgagcaatgagatac & & \\
\hline \multirow[t]{2}{*}{ hv1016 } & Accttgactacacttccattgttg & 99 & $95-99$ \\
\hline & Cgaacctgttgttcacgctca & & \\
\hline \multirow[t]{2}{*}{ hv1018 } & Tgtggctgtgacagatgtatgc & 470 & $344-470$ \\
\hline & Catttgggtgtttgtttcctga & & \\
\hline \multirow[t]{2}{*}{ hv1019 } & Gaagatctgccgtccaggtta & 185 & $170-185$ \\
\hline & rgctaggttttgttyctttgct & & \\
\hline \multirow[t]{2}{*}{ hv1020 } & Gggtggcatccaaattttcc & 272 & $244-278$ \\
\hline & Ttggctcmmgggagaatatgct & & \\
\hline \multirow[t]{2}{*}{ hv1021 } & Gggtggcatccaaattttcc & 303 & $277-303$ \\
\hline & Cacatcyaaatgctacctgcaa & & \\
\hline \multirow[t]{2}{*}{ hv1022 } & Tatgattcattgaccccrcacg & 272 & $244-278$ \\
\hline & Ccttgcatcaaggtttgtgcta & & \\
\hline \multirow[t]{2}{*}{ hv1023 } & Cagacagttcacccataagct & 130 & $109-130$ \\
\hline & Ccttgcatcaaggtttgtgcta & & \\
\hline
\end{tabular}

Intron III was cloned by PCR using primers of forward 5'-GTTATCGTCGACATTGAAGTAGGACT-3' and reverse 5'-GCTTTGAAGTCTGCTTGTAGGTATTT-3' (Vinje et al. 2010) with PCR program of $95^{\circ} \mathrm{C} 5 \mathrm{~min}, 95$ 
${ }^{\circ} \mathrm{C} 45 \mathrm{~s}, 50^{\circ} \mathrm{C} 30 \mathrm{~s}, 72{ }^{\circ} \mathrm{C} 1 \mathrm{~min}$ ( $\left.35 \mathrm{cycles}\right), 72{ }^{\circ} \mathrm{C} 10 \mathrm{~min}$, and $12{ }^{\circ} \mathrm{C}$ forever. PCR products were sequenced using Sanger method. All the fragments were aligned in DNAStar using Clustal W referring to the sequence of Huruna Nijo (D49999). All the genotypes or accessions in this study could be divided into three allele-types, Bmy1.a, Bmy1.b and Bmy1.c (Table 2) (Vinje et al., 2010).

Table 2

Bmy 1 intron III polymorphisms for 125 barley genotypes, Haruna Nijo was used as a reference.

\begin{tabular}{|c|c|c|c|c|c|c|c|c|}
\hline $\begin{array}{l}\text { Intron } \\
\text { III allele }\end{array}$ & $126 \mathrm{bp}$ & $38 \mathrm{bp}$ & $11 \mathrm{bp}$ & $21 \mathrm{bp}$ & Cultivated barley & NO. & Wild barley & NO. \\
\hline Bmy1.a & + & + & - & + & $\begin{array}{l}\text { Q33, Q1, Q146, Q24, } \\
\text { Q19, Q145, Q13, Q77, } \\
\text { D24, D90, Q8, Q9, D31, } \\
\text { Q222, D15, D27, D44, } \\
\text { Q64, D72, D57, D 65, } \\
\text { D33, Q66, D68, D25, } \\
\text { Q65, D28 }\end{array}$ & 27 & $\begin{array}{l}\text { XZ171, XZ178, } \\
\text { XZ172, XZ26, } \\
\text { XZ50, XZ126, } \\
\text { XZ103 }\end{array}$ & 7 \\
\hline Bmy1.b & - & + & - & - & $\begin{array}{l}\text { Q26, Q151, D69, Q16, } \\
\text { D67, D84, D64, D71, } \\
\text { Triumph, TL43 }\end{array}$ & 10 & $\begin{array}{l}\text { XZ142, XZ80, } \\
\text { XZ150, XZ144, } \\
\text { XZ16, XZ34, } \\
\text { XZ145, XZ166, } \\
\text { XZ35, XZ117, } \\
\text { XZ37, XZ40, } \\
\text { XZ127, XZ51, } \\
\text { XZ78, XZ111, } \\
\text { XZ125, XZ118, } \\
\text { XZ99, XZ124, } \\
\text { XZ108, XZ102, } \\
\text { XZ131,XZ130, } \\
\text { XZ94, XZ147 }\end{array}$ & 26 \\
\hline Bmy1.c & - & + & + & + & $\begin{array}{l}\text { Q223, D41, Q73, Q18, } \\
\text { Q138, Q11, Q17, Q23, } \\
\text { Q224, Q143, D56, } \\
\text { Q149, Q79, D40, D55, } \\
\text { Q36, Q107, Q119, D76, } \\
\text { D83, D73, Q80, D59, } \\
\text { Q81, D6, D13, D39, } \\
\text { D36, D78, D8, D87, D9, } \\
\text { D22, D94, Q113, D10, } \\
\text { Haruna Nijo }\end{array}$ & 36 & $\begin{array}{l}\text { XZ140, XZ137, } \\
\text { XZ134,XZ136, } \\
X Z 73, X Z 17 \\
\text { XZ36, XZ122, } \\
\text { XZ114,XZ64, } \\
\text { XZ176, XZ152, } \\
\text { XZ165,XZ19, } \\
\text { XZ161,XZ1, } \\
\text { XZ25, XZ3, } \\
\text { XZ5 }\end{array}$ & 19 \\
\hline
\end{tabular}

In the previous study, we found that the Tibetan wild barley XZ147 was a drought tolerant genotype with the largest increase of $\beta$-amylase activity and smallest grain weight loss under water stress compared with other genotypes, and Triumph was a drought sensitive malting barley (Wu et al. 2015). In the present study, therefore, we sequenced the full Bmy 1 gene of XZ147 and Triumph to analyze the molecular difference between the wild and cultivated barley (Gong et al. 2013), in order to further identify the mRNA differences in SNP and amino acid substitution based on the cDNA of Huruna Nijo through Clustal W (Table 3). 
Table 3

mRNA and amino acid sequence alignment of Bmy 1 gene from a cultivated barley Triumph and a wild barley XZ147. Huruna Nijo was used as a reference.

\begin{tabular}{|llllllll|}
\hline Allele type & Genotypes & 343 & 495 & 698 & 1040 & 1289 & 1581 \\
\cline { 3 - 8 } & & $\mathrm{R} 115 \mathrm{C}$ & $\mathrm{D} 165 \mathrm{E}$ & $\mathrm{V} 233 \mathrm{~A}$ & L347S & V430A & M527I \\
\cline { 3 - 8 } Bmy1.b & Huruna Nijo & $\mathrm{C}(\mathrm{R})$ & $\mathrm{G}(\mathrm{E})$ & $\mathrm{T}(\mathrm{V})$ & $\mathrm{C}(\mathrm{S})$ & $\mathrm{C}(\mathrm{A})$ & $\mathrm{T}(\mathrm{M})$ \\
\cline { 2 - 7 } & $\mathrm{XZ147}$ & $\mathrm{C}(\mathrm{R})$ & $\mathrm{C}(\mathrm{D})$ & $\mathrm{C}(\mathrm{A})$ & $\mathrm{C}(\mathrm{S})$ & $\mathrm{T}(\mathrm{V})$ & $\mathrm{T}(\mathrm{M})$ \\
\cline { 2 - 7 } & Triumph & $\mathrm{T}(\mathrm{C})$ & $\mathrm{C}(\mathrm{D})$ & $\mathrm{T}(\mathrm{V})$ & $\mathrm{T}(\mathrm{L})$ & $\mathrm{T}(\mathrm{V})$ & $\mathrm{A}(\mathrm{I})$ \\
\hline
\end{tabular}

\section{Statistical analysis}

Statistical analysis was performed using SPSS Statistics 20 (IBM, New York, NY, USA). Hierarchical cluster analysis of 125 genotypes based on SSR markers was conducted with the method of averagelinkage-between-groups. Two-way variance analysis (ANOVA) was carried out to evaluate the significance among barley genotypes $(G)$, drought treatments $(E)$ and the interaction between genotype and drought treatment $(\mathrm{G} \times \mathrm{E})$.

\section{Results}

\section{Polymorphism of Bmy1 DNA}

SSR markers based on Bmy 1 intron III DNA sequence divided the cultivated barley into numerous small groups (Fig. 1), and the wild accessions were scattered over these groups. Unfortunately, there was no outstanding cluster found in the present study. Thus, based on our previous findings, XZ147 and Triumph were selected from the 125 barley genotypes for further analysis (Wu et al. 2015).

\section{Bmy1 gene intron III alleles}

Four INDELs of Bmy1 intron III alleles, 126-bp \38-bp\11-bp and 21-bp were identified in this study (Table 2). According to different combinations of the INDELs, the 125 barley accessions used in this study were classified into three allele-types: Bmy1.a, Bmy1.b and Bmy1.c, with no Bmy1.d allele being detected. Among these three allele-types, Bmy1.c group occupied the largest proportion of the barley accessions (consisting of 36 cultivated and 19 wild barley accessions), followed by Bmy 1.b (consisting of 10 cultivated and 26 wild barley accessions) and Bmy1.a (consisting of 27 cultivated and 7 wild barley accessions). It was surprising that half of the wild barley were classified into group Bmy1.b, but most of the cultivated barley were classified into group Bmy1.a and $c$.

\section{Polymorphism of Bmy1 cDNA and amino acid composition}

In this study, six SNPs and corresponding amino acid substitution were identified based on the alignment of cDNA between wild barley XZ147 and cultivated barley Triumph (Table 3). Wild barley XZ147 showed 
a great difference from Triumph and Huruna Nijo mRNA and amino acid composition, especially in D165E $(495 \mathrm{C} \rightarrow \mathrm{D})$ and V430A $(1289 \mathrm{~T} \rightarrow \mathrm{C})$.

\section{The effect of drought on $\beta$-amylase activity}

Under drought stress, the changing trend of $\beta$-amylase activities differed greatly between subspecies (cultivated $v s$ wild), allele-types or among genotypes (Fig. 2, Table 4-6). Impressively, $\beta$-amylase activities in all wild barley accessions were dramatically increased by $6.4-81.2 \%$, whereas significantly decreased (about 20\%) in cultivated barley genotypes (Fig. 2). Furthermore, the impact of drought stress on $\beta$-amylase activity also showed a variation between the three allele-types. In Bmy 1.b group, none of the cultivated barley genotypes was observed the decrease in $\beta$-amylase activity under drought stress relative to the control (Fig. 2B, Table 5) and $\beta$-amylase activities decreased in only $20 \%$ cultivated genotypes from either Bmy1.a or Bmy1.c group (Fig. 2A and C, Tables 4 and 6). Both XZ147 and Triumph, which belong to Bmy 1.b group, showed increases of $\beta$-amylase activity by $76.8 \%$ and $20.3 \%$ under drought stress in comparison with the control, respectively (Fig. 3).

Table 4

The distribution of grain $\beta$-amylase activity of Bmy1.a alleles.

\begin{tabular}{|c|c|c|c|c|}
\hline & \multicolumn{4}{|c|}{$\beta$-amylase activity } \\
\hline & \multicolumn{2}{|c|}{ Cultivated barley } & \multicolumn{2}{|c|}{ Wild barley } \\
\hline & Control & Drought & Control & Drought \\
\hline Average & 926.83 & 983.04 & 974.41 & 1410.73 \\
\hline Maximum & 1513.57 & 1991.69 & 1472.34 & 2467.18 \\
\hline Minimum & 465.81 & 394.42 & 705.63 & 975.86 \\
\hline Max/Min & 3.25 & 5.05 & 2.09 & 2.53 \\
\hline CV \% & $31.09 \%$ & $40.26 \%$ & $34.97 \%$ & $37.07 \%$ \\
\hline G & 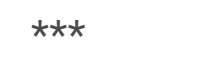 & $\star \star \star \star$ & $\star \star \star \star$ & $\star \star \star$ \\
\hline$E$ & $\star \star \star \star ~$ & & $\star \star \star \star$ & \\
\hline $\mathrm{G} \times \mathrm{E}$ & $\star \star \star *$ & & & \\
\hline \multicolumn{5}{|c|}{$\begin{array}{l}\text { CV: Coefficient of variation; G: Significance of difference between genotypes; E: Significance o } \\
\text { difference between treatments (control vs. drought); } \mathrm{G} \times \mathrm{E} \text { : Interaction between genotype and } \\
\text { environment. }\end{array}$} \\
\hline
\end{tabular}


Table 5

The distribution of grain $\beta$-amylase activity of $B m y 1 . b$ alleles.

\begin{tabular}{|c|c|c|c|c|}
\hline & \multicolumn{4}{|c|}{$\beta$-amylase activity } \\
\hline & \multicolumn{2}{|c|}{ Cultivated barley } & \multicolumn{2}{|c|}{ Wild barley } \\
\hline & Control & Drought & Control & Drought \\
\hline Average & 1173.23 & 1548.07 & 356.17 & 1236.42 \\
\hline Maximum & 2322.76 & 3091.99 & 699.97 & 2467.18 \\
\hline Minimum & 534.94 & 709.65 & 131.47 & 590.87 \\
\hline Max/Min & 4.34 & 4.36 & 5.32 & 4.18 \\
\hline CV \% & $49.7 \%$ & $42.41 \%$ & $25.29 \%$ & $27.86 \%$ \\
\hline G & $\star \star \star$ & $\star \star \star *$ & $\star \star \star *$ & $\star \star \star ~$ \\
\hline$E$ & $\star \star \star ~$ & & $\star \star \star *$ & \\
\hline$G \times E$ & $\star \star \star ~$ & & & \\
\hline \multicolumn{5}{|c|}{$\begin{array}{l}\text { CV: Coefficient of variation; G: Significance of difference between genotypes; E: Significance of } \\
\text { difference between treatments (control vs. drought); G } \times \text { E: Interaction between genotype and } \\
\text { environment. }\end{array}$} \\
\hline$\star \star \star$ Significa & $\%$ probabil & & & \\
\hline
\end{tabular}


Table 6

The distribution of grain $\beta$-amylase activity of Bmy1.c alleles.

\begin{tabular}{|c|c|c|c|c|}
\hline & \multicolumn{4}{|c|}{$\beta$-amylase activity } \\
\hline & \multicolumn{2}{|c|}{ Cultivated barley } & \multicolumn{2}{|c|}{ Wild barley } \\
\hline & Control & Drought & Control & Drought \\
\hline Average & 892.12 & 908.57 & 356.17 & 1236.42 \\
\hline Maximum & 1904.21 & 1472.34 & 699.97 & 2467.18 \\
\hline Minimum & 111.86 & 404.47 & 131.47 & 590.87 \\
\hline Max/Min & 17.02 & 3.64 & 5.32 & 4.18 \\
\hline $\mathrm{CV} \%$ & $32.27 \%$ & $29.73 \%$ & $42.46 \%$ & $50.18 \%$ \\
\hline G & $\star \star \star$ & $\star \star \star \star$ & $\star \star \star *$ & $\star \star \star$ \\
\hline$E$ & $\star \star \star$ & & $\star \star \star *$ & \\
\hline$G \times E$ & $\star \star \star$ & & & \\
\hline \multicolumn{5}{|c|}{$\begin{array}{l}\text { CV: Coefficient of variation; G: Significance of difference between genotypes; E: Significance of } \\
\text { difference between treatments (control vs. drought); G } \times \text { E: Interaction between genotype and } \\
\text { environment. }\end{array}$} \\
\hline 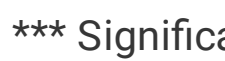 & $\%$ probabi & & & \\
\hline
\end{tabular}

\section{Discussion}

Marker-assisted selection (MAS) has already been widely used in breeding, phyletic evolution, comparative genetics and gene mapping (Prasad et al. 2000; Stein and Graner 2004; Varshney et al. 2005). Sufficient evidences have demonstrated the usefulness of MAS in accelerating breeding efficiency (Crepieux et al. 2005; Koebner and Summers 2003). In this study, SSR assay of Bmy 1 DNA sequences showed abundant polymorphisms of the gene (Fig. 1). Genetic cluster and the distribution of $\beta$-amylase activity (Table 2, 4-6) showed that the Tibetan wild barley is randomly scattered over various Bmy 1 groups of cultivated barley, rather than a specific cluster group. Moreover, more abundant polymorphisms of the wild barley ( $H$. vulgare subsp. spontaneum) could be observed, in comparison with the cultivated barley (Hordeum vulgare L.).

According to the presence and absence of the INDELs of 126-, 38-, 11- and 21-bp, the 125 barley accessions could be divided into three allele-types: Bmy 1.a\Bmy1.b and Bmy1.c (Table 2). The presence of 126-bp囚38-bp and 21-bp INDELs, and the absence of 11-bp INDEL was defined as Bmy1.a; the presence of 38-bp and absence of 126-bp, 11-bp and 21-bp INDELs as Bmy1.b; the absence of 126-bp and the presence of 38-bp, 11-bp and 21-bp INDELs as Bmy1.c (Vinje et al.,2010). The allele-type with the presence of 11- and 21-bp, and the absence of 126- and 38-bp INDELs was defined as Bmy1.d, which was 
once identified in a wild barley PI 2976897 (Erkkilä et al. 1998). In this study, no Bmy1.d was detected in all barley genotypes. The impact of drought on $\beta$-amylase activity in grains varied greatly between genotypes. All genotypes belonging to Bmy 1.b, and the wild barley accessions belonging to Bmy 1.a and $B m y$ 1.c showed an increase in $\beta$-amylase activity, while the cultivated barley genotypes belonging to Bmy1.a and Bmy1.c showed a decrease in $\beta$-amylase activity. Bmy1 intron III has been reported to be a useful marker in barley breeding for selecting high malt quality (Kaneko and Kihara 2000) and the 126-bp INDEL is closely correlated to $\beta$-amylase activity and thermo-stability (Coventry et al. 2003; Erkkilä et al. 1998; Erkkilä 1999; Kaneko et al. 2000; Gunkel et al. 2002). The 126-bp fragment in Bmy1.a allele-type may be a site of negatively regulated transcription factor, and could be linked with the low $\beta$-amylase activity (Erkkilä and Ahokas 2001). The current result also confirmed that determining Bmy 1 intron III allele-type could help predict $\beta$-amylase activity under drought stress. In this study, all genotypes of Bmy 1.b allele-type showed an increase in grain $\beta$-amylase activity, while those of Bmy1.a and Bmy1.c allele-types showed less changes, indicating that the genotypes belonging to Bmy $1 . b$ allele-type could be more useful in developing the barley cultivars with drought tolerance and high malt quality.

It has been documented that some amino acid substitutions derived from specific SNPs of mRNA in Bmy 1 gene were highly correlated with $\beta$-amylase activity in barley grains (Chiapparion et al. 2006; Filichkin et al. 2010; Ma et al. 2001; Zhang et al. 2007). Zhang et al. (2007) and Ma et al. (2001) reported that $115^{R \rightarrow C}$ amino acid substitution was the main reason for high $\beta$-amylase activity of W127 and Ashqeleon. Chiapparino et al. (2006) found that the genotypes containing amino acid composition of $\mathrm{C} 115, \mathrm{E} 165$ and V233 had higher $\beta$-amylase activity than the ones with the composition of R115, D165 and A233. Based on the alignment of Bmy1 gene DNA, Filichkin et al. (2010) identified two genotypes only differing in $\mathrm{V} 233 \mathrm{~A}$, with the genotypes $\mathrm{A} 233$ having higher $\beta$-amylase activity than the genotype V233. R115 or C115 alone had no effect on $\beta$-amylase activity, but their co-existence increased $\beta$-amylase activity and thermo-stability distinctly (Clark et al. 2003; Ma et al. 2001). In this study, $\beta$-amylase activity was higher in cultivated barley Triumph than wild barley XZ147 under normal condition, which may be attributed to the amino acid composition of C115, D165 and V233. Surprisingly, $\beta$-amylase activity was higher in XZ147 than Triumph under drought stress, which might result from its unique M527 or the composition of R115, D165, A233, S347 and M527. In addition, drought-induced increase in the abundance of $\beta$-amylase might also cause such increase in its activity. Therefore, the association of the amino acid M527 or the composition of R115, A233, S347 and M527 allele with the increase in $\beta$-amylase activity under drought stress, and their potentiality A233 in breeding barley cultivars with both drought tolerance and high $\beta$-amylase activity in grain need to be further studied.

\section{Conclusion}

Novel genetic variation is essential for successful breeding. In this study, based on the comparison of genetic variation of Bmy 1 gene from both cultivated and wild barley, we evaluated the potential value of wild barley in developing cultivars with drought tolerant and high $\beta$-amylase activity. Introns play important roles in the functioning of genes or genomes, participate in the regulation of auto-catalytic 
activity of IREs (Intronic Regulatory Elements), and the mobility of endonucleases and reverse transcriptases (Lewin 2004); however, this still needs further study (Yutzey et al. 1989). In plants, introns regulate the transcription of genes, such as, in rice (Fiume et al. 2004) and Arabidopsis (Gazzani et al. 2003; Sheldon et al. 2002). In this study, $\beta$-amylase activity of Bmy $1 . b$ allele-type accessions was increased by drought treatment, indicating its higher implication value in malt barley breeding than the other two allele-types. Meanwhile, wild barley belonging to Bmy $1 . b$ allele type displayed higher $\beta$-amylase activity and minimum yield lose under drought stress (Wu et al. 2015). This might result from its unique amino acid substitution M527 or the amino acid composition of R115, D165, A233, S347 and M527. We conclude that the gene pool of Tibetan wild barley germplasm may provide a unique resource for improving drought tolerance and grain $\beta$-amylase activity of malt barley.

\section{Declarations}

\section{Conflict of Interest}

The authors declare that they have no conflict of interest. This article does not contain any studies with human participants or animals performed by any of the authors. Informed consent was obtained from all individual participants included in the study.

\section{References}

Arends AM, Fox GP, Henry RJ, Marschke RJ, Symons MH (1995) Genetic and environmental variation in the diastatic power of Australian barley. J Cereal Sci 21:63-70.

Chiapparino E, Donini P, Reeves J, Tuberosa R, O'Sullivan DM (2006) Distribution of beta-amylase I haplotypes among European cultivated barleys. Mol Breeding 18:341-354.

Clark SE, Hayes PM, Henson CA (2003) Effects of single nucleotide polymorphisms in $\beta$-amylase1 alleles from barley on functional properties of the enzymes. Plant Physiol Bioch 41:798-804.

Coventry SJ, Collins HM, Barr AR, Jefferies SP, Chalmers KJ, Logue SJ, Langridge P (2003) Use of putative QTLs and structural genes in marker assisted selection for diastatic power in malting barley (Hordeum vulgare L.). Aust J Agr Res 54:1241-1250.

Crepieux S, Lebreton C, Flament P, Charmet G (2005) Application of a new IBD-based QTL mapping method to common wheat breeding population: analysis of kernel hardness and dough strength. Theor Appl Genet 111:1409-1419.

Dai F, Nevo E, Wu D, Comadran J, Zhou M, Qiu L, Chen Z, Beiles A, Chen G, Zhang G (2012) Tibet is one of the centers of domestication of cultivated barley. PNAS 109:16969-16973.

Dai HX, Shan WN, Zhao J, Zhang GP, Li CD, Wu FB (2011) Difference in response to aluminum stress among Tibetan wild barley genotypes. J Nutr Soil Sci 174:952-960. 
Delcour JA, Verschaeve SG (1987) Malt diastatic activity. II. A modified EBC-diastatic power assay for the selective estimation of $\beta$-amylase activity, time, and temperature dependence of the release of reducing sugars. J I Brewing 93:296-301.

Eglinton JK, Langridge P, Evans DE (1998) Thermostability variation in alleles of barley beta-amylase. J Cereal Sci 28:301-309.

Erkkilä MJ, Ahokas H (2001) Special barley $\beta$-amylase allele in a Finnish landrace line HA52 with high grain enzyme activity. Hereditas 134:91-95.

Erkkilä MJ, Leah R, Ahokas H, Cameron-Mills V (1998) Allele-dependent barley grain $\beta$-amylase activity. Plant Physiol 117:679-685.

Erkkilä MJ (1999) Intron III-specific markers for screening of $\beta$-amylase alleles in barley cultivars. Plant Mol Biol Rep 17:139-147.

Filichkin TP, Vinje MA, Budde AD, Corey AE, Duke SH, Gallagher LW, Helgesson J, Henson AC, Obert DE, Ohm JB, Petrie S, Ross A, Hayes P (2010) Phenotypic variation for diastatic power, beta-amylase activity, and beta-amylase thermostability vs. allelic variation at the Bmy 1 locus in a sample of North American barley germplasm. Crop Sci 50:826-834.

Fiume E, Christou P, Giani S, Beviarion D (2004) Introns are key regulatory elements of rice tubulin expression. Planta 218:693-703.

Franckowiak JD, Lundqvist U (2008) Rules for nomenclature and gene symbolization in barley. Barley Genet NewsI 38:165-170.

Gazzani S, Gendali AR, Lister C, Dean C (2003) Analysis of the molecular basis of flowering time variation in Arabidopsis accessions. Plant Physiol 132:1107-1114.

Gibson TS, Solah V, Holmes MRG, Taylor HR (1995) Diastatic power in malted barley-contributions of malt parameters to its development and the potential of barley grain $\beta$-amylase to predict malt diastatic power. J I Brewing 101:277-280.

Gong X, Westcott S, Zhang XQ, Yan GJ, Lance R, Zhang GP, Sun DF, Li CD (2013) Discovery of novel Bmy1 Alleles increasing $\beta$-amylase activity in Chinese landraces and Tibetan wild barley for improvement of malting quality via MAS. PLOS ONE 8:e72875.

Gunkel J, Voetz M, Rath F (2002) Effect of the malting barley variety (Hordeum vulgare L.) on fermentability. J I Brewing 108:355-361.

Hayden MJ, Nguyen TM, Waterman A, McMichael GL, Chalmers KJ (2008) Application of multiplex-ready PCR for fluorescence-based SSR genotyping in barley and wheat. Mol Breeding 21:271-281. 
Hayes PM, Liu BH, Knapp SJ, Chen F, Jones B, Blake T, Franckowiak J, Rasmusson D, Sorrells M, Ullrich SE, Wesenberg D, Kleinhofs A (1993) Quantitative trait locus effects and environmental interaction in a sample of North American barley germplasm. Theor Appl Genet 87:392-401.

Kaneko T, Kihara M, Ito K (2000) Genetic analysis of $\beta$-amylase thermostability to develop a DNA marker for malt fermentability improvement in barley, Hordeum vulgare. Plant Breeding 119:197-201.

Koebner RMD, Summers RW (2003) $21^{\text {st }}$ century wheat breeding: plot selection or plate selection? Trends Biotechnol 21:59-63.

Kreis M, Williamson MS, Shewry PR, Sharp P, Gale M (1988) Identification of a second locus encoding $\beta$ amylase on chromosome 2 of barley. Genet Res 51:13.

Lewin B (2004) Genes VIII. Pearson, Prentice Hall.

Li CD, Langridge P, Zhang XQ, Eckstein PE, Rossnagel BG, Lance RCM, Lefol EB, Lu MY, Harvey BL, Scole GJ (2001) Mapping of barley (Hordeum vulgare L.) beta-amylase alleles in which an amino acid substitution determines beta-amylase isoenzyme type and the level of free beta-amylase. $\mathrm{J}$ Cereal Sci 35:39-50.

Ma YF, Evans DE, Logue SJ, Langridge P (2001) Mutations of barley $\beta$-amylase that improve substratebinding affinity and thermostability. Mol Genet Genomics 266:345-352.

McCleary BV, Codd R (1989) Measurement of $\beta$-amylase in cereal flours and commercial enzyme preparations. J Cereal Sci 9:17-33.

Nielsen G, Johansen H, Jensen J, Hejgaard J (1983) Localization on barley chromosome 4 of genes coding for $\beta$-amylase (Bmy1) and protein Z (Paz1). Barley Genet Newsl 13:55-57.

Paris M, Jones MGK, Eglinton JK (2002) Genotyping single nucleotide polymorphisms for selection of barley $\beta$-amylase alleles. Plant Mol Biol Rep 20:149-159.

Powling A, Islam AKMR, Shepherd KW (1981) Isozymes in wheat-barley hybrid derivative lines. Biochem Genet 19:237-254.

Prasad M, Varshney RK, Roy JK, Balyan HS (2000) The use of microsatellites for detecting DNA polymorphisms, genotype identification and genetic diversity in wheat. Theor Appl Genet 100:584-592.

Qiu L, Wu D, Ali S, Cai S, Dai F, Jin X, Wu F, Zhang G (2011) Evaluation of salinity tolerance and analysis of allelic function of HvHKT1 and HvHKT2 in Tibetan wild barley. Theor Appl Genet 122:695-703.

Sheldon CC, Conn AB, Dennis ES, Peacock WJ (2002) Different regulatory regions are required for the vernalization-induced repression of FLOWERING LOCUS C and for the epigenetic maintenance of repression. Plant Cell 14:2527-2537. 
Sjakste TG, Zhuk AF (2006) Novel haplotype description and structural background of the eventual functional significance of the barley $\beta$-amylase gene intron III rearrangements. Theor Appl Genet 113:1063-1079.

Stein N, Graner A (2004) Map-based gene isolation in cereal genomes. In: Gupta PK, Varshney RK (eds) Cereal genomics. Kluwer, Dordrecht, pp.331-360.

Varshney RK, Sigmund R, Borner A, Korzun V, Stein N, Sorrells ME, Langridge P, Graner A (2005) Interspecific transferability and comparative mapping of barley EST-SSR markers in wheat, rye and rice. Plant Sci 168:195-202.

Vinje MA, Duke SH, Henson CA (2010) Utilization of different Bmy1 intron III alleles for predicting $\beta$ amylase activity and thermostability in wild and cultivated barley. Plant Mol Biol Rep 28:491-501.

Wei K, Jin X, Chen X, Wu F, Zhou W, Qiu B, Qiu L, Wang X, Li C, Zhang G (2009) The effect of $\mathrm{H}_{2} \mathrm{O}_{2}$ and abscisic acid (ABA) interaction on $\beta$-amylase activity under osmotic stress during grain development in barley. Plant Mol Biol Rep 47:778-784.

Wu XJ, Chen X, Zeng FR, Zhang GP (2015) The genotypic difference in the effect of water stress after anthesis on the malt quality parameters in barley. J Cereal Sci 65:209-214.

Yoshigi N, Okada Y, Sahara H, Koshino S (1994) PCR cloning and sequencing of the $\beta$-amylase cDNA from barley. J Biochem 115:47-51.

Yutzey KE, Kline RL, Konieczny SF (1989) An internal regulatory element controls troponin I gene expression. Mol Cell Biol 9:137-1405.

\section{Figures}




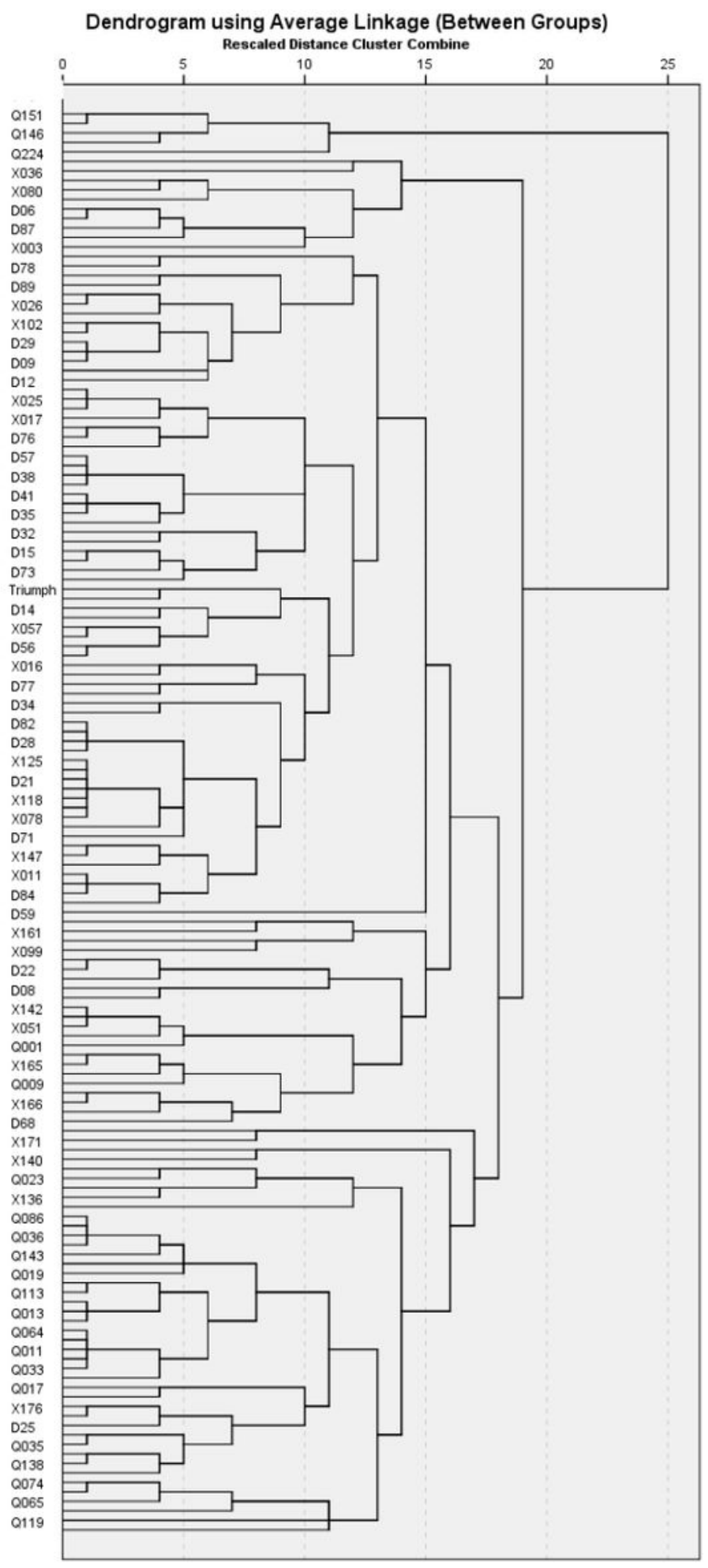

Figure 1

Genetic cluster of 125 barley accessions by SSR markers. 

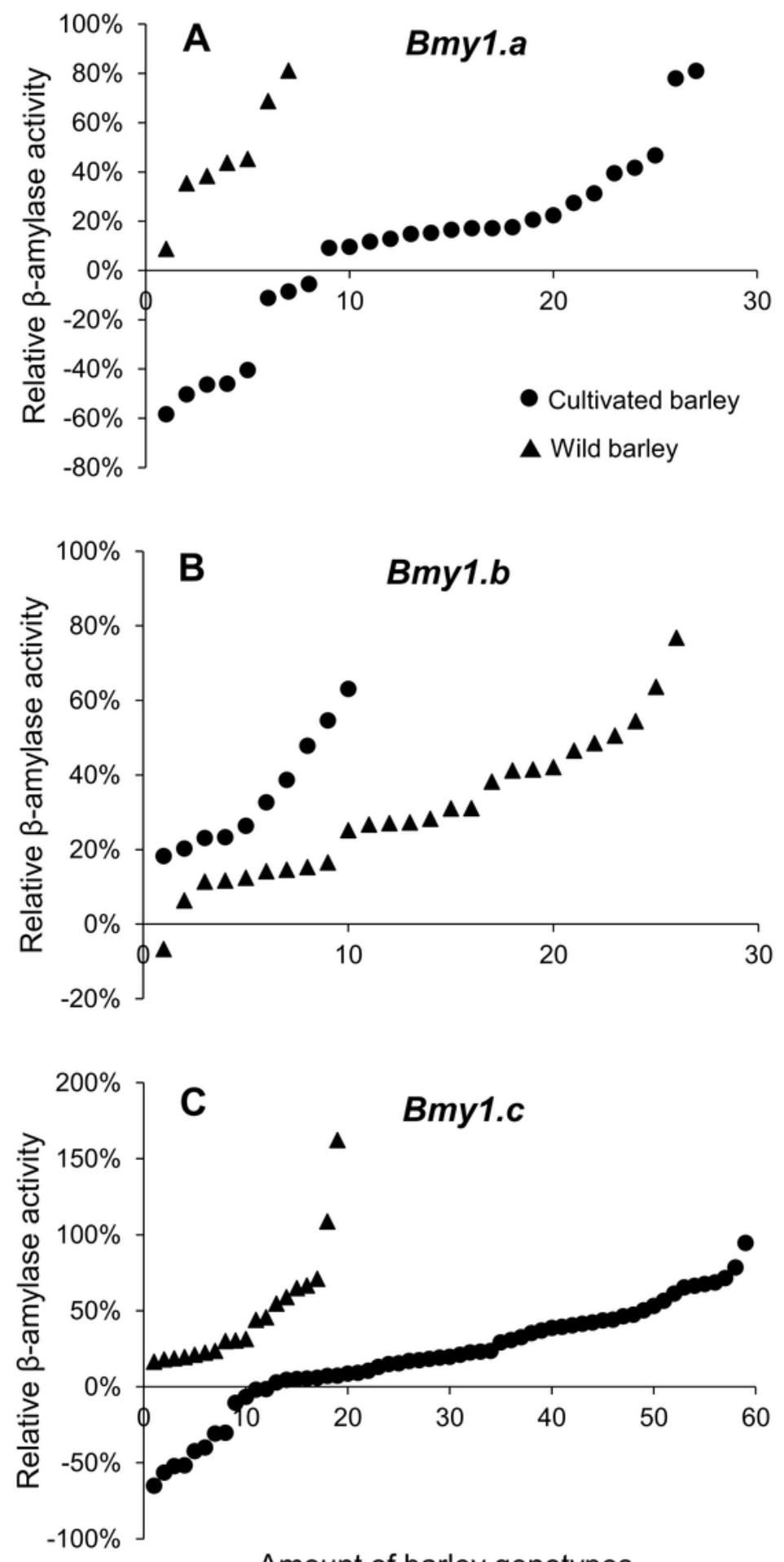

Amount of barley genotypes

Figure 2

The effect of drought stress on grain $\beta$-amylase activity of 125 barley genotypes. A, Bmy1.a alleles; $B$, Bmy1.b alleles; C, Bmy1.c alleles. 


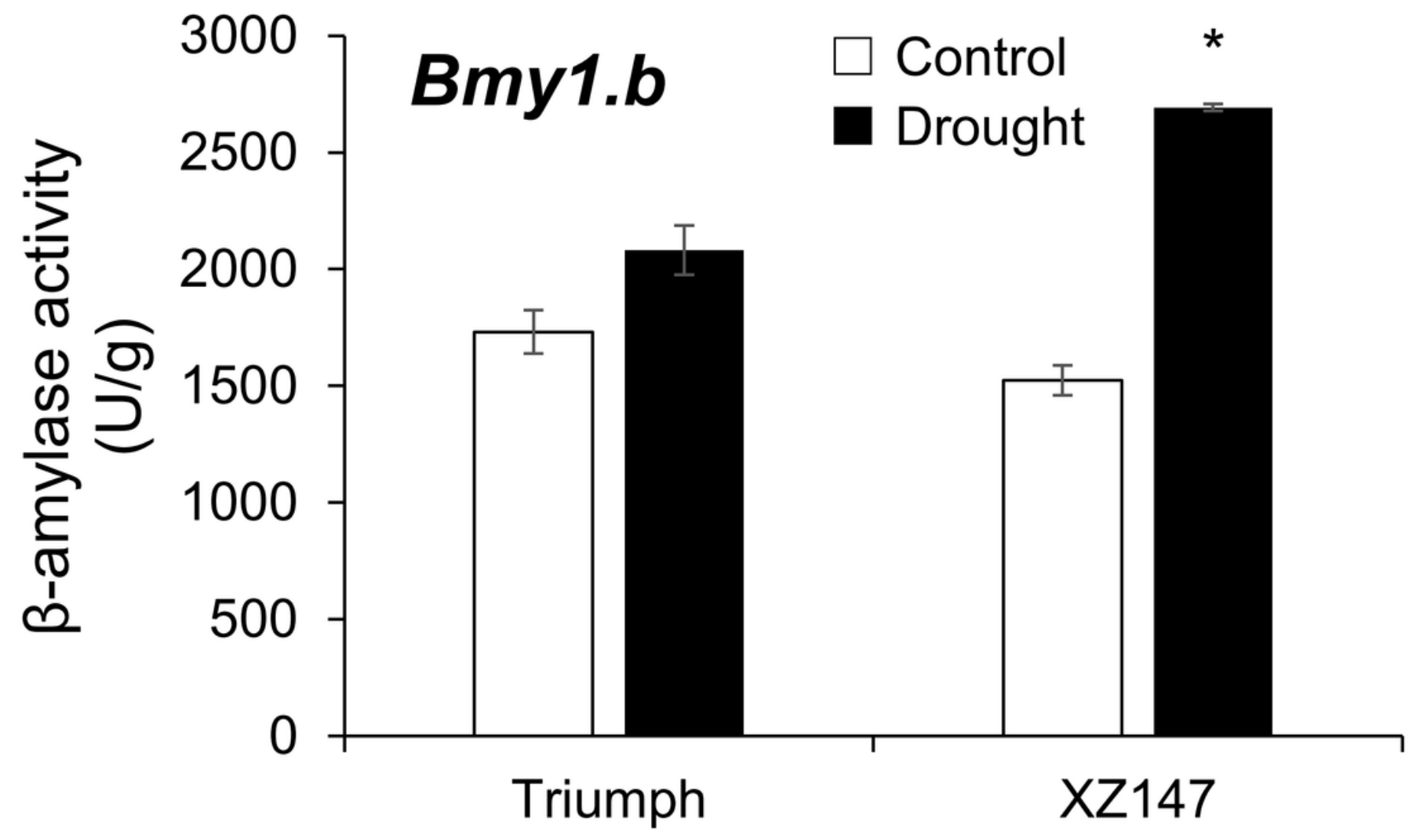

Figure 3

The effect of drought stress on $\beta$-amylase activity in barley grains. *, significant at $95 \%$ probability.

\section{Supplementary Files}

This is a list of supplementary files associated with this preprint. Click to download.

- Tables1.doc 